\title{
Tales from the crypt: might cryptocurrencies spell the death of traditional money? - A quantitative analysis -
}

\author{
Cristian STEFAN \\ cristianstefan1984@yahoo.com
}

\begin{abstract}
Cryptocurrencies have experienced an exponential growth trend in the past 24 months, followed by a big crash. In the early years of the Internet, inspired entrepreneurs such as Jeffrey Bezos realized that, when something grows exponentially, it becomes ubiquitous within a short time span. Similarly to the Internet in 1994, cryptocurrencies have recently been growing at a dazzling rate, thus one can expect them to be used on a global scale very soon, in spite of the last bubble which has already burst. Alternative currencies are greeted with great enthusiasm, due to their potential to return financial power back to the people, especially in the context of general dissatisfaction and disappointment with the banking sector. They bring about several advantages, such as financial innovations, lower fees as well as increased availability to developing populations. At the same time, their high volatility and lack of supervision might imply that they only serve as complementary financing and not as a substitute of traditional banking. This article discusses the development of cryptocurrencies, including aspects related to Bitcoin, financial technology and the blockchain. Using historical data from Coinmarketcap.com between April 2013 and February 2018, I run a quantitative analysis of the distributions and evolution over time for all listed cryptocurrencies with known market capitalization. I look at the interplay between number of cryptocurrencies and market value, at growth rates, cumulative shares and volatility. I find a phenomenon of exponential growth and violent volatility, which I explain in light of cryptocurrencies' strengths and weaknesses, as identified in the literature. I emphasize the importance of cryptocurrencies in the context of the global digital economy and I discuss future implications.
\end{abstract}

Keywords: Cryptocurrencies, alternative currencies, digital currencies, Fintech, Bitcoin, blockchain, coin market cap

\section{Introduction}

In the context of a lingering global financial crisis, the need to reform the financial system is becoming ever more stringent. The recent technological revolution brought about financial innovations which have the potential to democratize the access to finance. Among these innovations, cryptocurrencies are seen as a new hope to become warrants of value without the need for intermediation by traditional banks. The present study shows the strengths and weaknesses of alternative currencies, especially in light of the most recent developments. The study performs a quantitative analysis and enhances our perspective on cryptocurrency development by using a wider time horizon than existing studies. The analysis covers the period between April 2013 and February 2018 and focuses mainly on the interplay between the number of cryptocurrencies and market capitalization. The phenomenon I observe is one of exponential growth combined with violent volatility. I explain this result using arguments from the literature review.

The remainder of the paper is structured as follows: the chapter on literature reviews presents the general background for the analysis, introduces the most important concepts and discusses the main advantages and disadvantages of alternative finance and 
cryptocurrencies. The subsequent two chapters describe the employed methodology and present the main results. The final chapter concludes and provides an outlook.

\section{Literature review General background}

The global financial system is nowadays facing some of the biggest challenges in its PICBE | 919 existence. Dula and Lee (2017) point out to the inefficacy of the system to support economic growth and reduce debt, despite trillions of dollars being pumped into the system by governments since the beginning of the global financial crisis. The financial regime is being attacked on multiple fronts, with interest rates close to zero, while "new, nimbler competitors are chipping away at the financial industries' bread and butter by offering alternative services better suited for various customer segments" (idem, p.2).

A battle is being fought between incumbents of the traditional banking industry and alternative providers of financial services. Nowhere is this battle more visible than on its main front: the e-commerce and payments industry (idem). Dula and Lee (2017) state that "in the new economy trust is the currency that matters more than ever" (p. 9) and they extensively describe cases of companies and services which successfully satisfied the enormous demand for secure online transactions: Paypal, Google Wallet or Apple Pay (idem). Moreover, the authors emphasize that we are experiencing "a democratization of access" to finance, because "in almost every market, rich or poor, smartphone penetration is nearly complete" and most transactions as well as payments no longer require credit cards, but can be performed via smartphones (idem, p.8). It must be noted that it was the Internet start-ups and telecommunication companies which initiated this revolution and included the developing populations into financial services, and not the banks (idem, pp. 9-10). The next section introduces the main technologies which made the revolution possible.

\section{Definitions of basic concepts: Fintech, blockchain and cryptocurrencies}

The Guardian (03.02.2015) defines Fintech as "the application of technology in financial services to create disruptive business models and inclusive products". Inclusion in this context refers to new access to banking for customers who previously were excluded from it. However, the disruption induced by Fintech "creates winners and losers" - that is, "some banks will thrive and others will find it hard to adapt" (idem). Fintech is most likely to become a complement to the services offered by incumbent banks, rather than an element that would "render traditional banking redundant" (idem). Fintech is a global phenomenon, albeit in its infancy, and it is growing in proportions fast, with investments rising threefold from around $\$ 4$ billion in 2013 to about \$ 12 billion in 2014 (Accenture, 2015). More details about the advantages of Fintech are available in the next section.

A blockchain is a method of recording digital data using "a logbook approach" and it consists of a "cryptographically linked chain of blocks of data", where "blocks are chained in a sequence using cryptographic hashes", and "a hash is a fixed length number derived from a given message or document" (Leon et al., 2017, pp. 288-289). Overly simplified, a blockchain stores information about the content of a transaction as well as its metadata. The blockchain system is based on an "automated peer-to-peer computer network", so that the details of any transaction are recorded across thousands of computers and thus a transaction can only be approved once the nodes of the network "reach a consensus", which should ensure certainty over the security of the transaction (Dula and Lee, 2017, p. 15). 
However, Leon et al. (2017) warn about the widespread misconception, found even in academia, "that blockchains are immutable or unchangeable, and that transactions in a blockchain cannot be modified". According to the authors, "an agent or set of agents with a sufficient amount of computing power" can modify a blockchain, "perhaps collaboratively" (idem). Moreover, algorithms that are "cryptographically secure" now may not be secure as time passes and computing power advances (idem).

PICBE $\mid 920$

A cryptocurrency based on blockchain technology is a warrant of value, independent of the form this value might take: "a company share, tax or environmental credits, vouchers, cash, votes" (Dula and Lee, 2017, p. 15). Alternative currencies "represent value for a particular community that uses them as a means of exchange" and none of them have ever been adopted by any government as legal currency; however, some of them such as Bitcoin are exchangeable with fiat money (Baron et al., 2015, p. 8). They may take forms such as "money used in online games or frequent-flier miles" (idem, p. 8). Unlike traditional money, cryptocurrencies are, by definition, based on decentralized systems, due to the nature of the underlying blockchain described above, which makes them efficient and resilient. The first cryptocurrency, Bitcoin, was released in 2009 and gained widespread adoption because it was perceived as secure and anonymous (idem, p.11). Further cryptocurrencies, named Altcoins, followed in the years to come. Many of them "were effectively Ponzi schemes, with the creators using them to pump-and-dump the new currency" (idem, p. 15). Cryptocurrencies are similar to a two-edged sword: they hold great potential for good and for bad. This is discussed in the next sections.

\section{Advantages of alternative financing}

Some of the main advantages of Fintech, which are used by innovative technology and ecommerce companies but not by traditional banks, are the following: lower operational costs, lower capital requirements and fewer compliance regulations (Dula and Lee, 2017). Moreover, Internet companies have incorporated Fintech through highly automated digital infrastructures with millions of active users, reviews, user profiles, creditworthiness data and logistic data (idem). The default rate of the customers involved in such systems is typically very low, meaning that almost all customers pay back their loans (idem). Traditional banks have no access to such infrastructures; instead, they cling to "legacy systems", which have been developed over generations and which cannot be reformed fast enough to keep up with the pace of technological progress (idem).

Lee and Teo (2015) identify five principles of successful Fintech, which also show the advantages of the technology compared to traditional banking: i) low profit margins combined with network effects and building critical mass; ii) asset light businesses which do not build on large fixed costs; iii) scalability is easier to achieve with online business, as the necessity for physical units is reduced; iv) innovativeness through the use of mobile technologies and applications; v) ease of compliance via low capital requirements and less strict regulation. All these five advantages are typical to Fintech but cannot be easily incorporated into traditional banks, as their business models work on the opposite principles: banks do not tap low-profit markets, they need high fixed costs and capital requirements to set up, rely more on physical presence, do not have digital infrastructure adapted to e-commerce (thus, they missed out on the first-mover advantages associated with it) and they are subject to heavy regulation. 
The Guardian (03.02.2015) suggests that Fintech increases the social good, due to the inclusion of new customers, especially in developing countries, who previously were not eligible for the "formal banking sector". Innovations created by Fintech include: money transfers via mobile phones, transfers overseas with low fees, as well as crowdfunding and microfinance schemes, which help entrepreneurs - all these were sectors in which traditional banks were not active (idem). The Guardian (07.07.2015) gives expression to the general public's dissatisfaction with the banking sector, which is viewed as "not only too big to fail and too big to jail, but simply too big to compete and unable to serve customers needs". The newspaper suggests that the public may now act on this dissatisfaction by using financial innovations such as peer-to-peer lending, Fintech which allows direct transfers between accounts without intermediation by banks, as well as cryptocurrencies which fill liquidity gaps in the economy (idem). Further advantages of alternative financing are, for instance, Fintech platforms based on cryptocurrencies and blockchain, "which are typically open access and have extraordinary potential to automate banking services while improving security and transparency", making fraudulent transactions almost impossible (Dula and Lee, 2017, pp. 14-15). Some cryptocurrencies further developed the blockchain technology, generated new technological applications and were appreciated for their efficiency, security and resilience as means of exchange (Baron et al., 2015). As exchange method in local communities, virtual currencies may carry a negative interest rate and support local businesses (Mikolajewicz-Wozniak and Scheibe, 2015). Last but not least, the inclusion of the previously un-banked masses through alternative finance offers the promise of reducing inequality and promoting economic growth (Dula and Lee, 2017).

\section{Criticism of cryptocurrencies}

While cryptocurrencies were greeted with great enthusiasm in the literature and the press around the year 2015, at the beginning of 2018 the tone changed significantly. Big investors such as Warren Buffet declared publicly that they would never invest in alternative currencies, and criticism of the currencies intensified, due to disadvantages such as volatility, deregulation, generating speculation and negative effects on the climate.

The Guardian (07.01.2018) warns that cryptocurrencies may be "useless as a medium of exchange because the price fluctuates violently and unpredictably". The newspaper also points out that cryptocurrencies are the ground of intense speculation, born out of "greed and gullibility", and of the widespread human desire to become rich overnight (idem). Another disadvantage is that the existence of cryptocurrencies depends on computer code and when the code is flawed, large amounts of (virtual) money may be stolen or disappear (idem). Decentralization and deregulation are further areas of criticism for cryptocurrencies. With traditional currency transfers, a central authority regulated by law ensures the authenticity of transactions and prevents cyberattacks (Leon et al., 2017). Differently, transfers of cryptocurrencies are performed in a decentralized manner between members of the network and transactions are approved through consensus in the network's blockchain; however, the blockchain may not be unique and different users may observe different blockchains (idem).

The use of the Bitcoin network generated a public scandal in January 2018, as it was signaled that the cryptocurrency consumed more energy than the entire Republic of Ireland, produced yearly more $\mathrm{CO}_{2}$ than one million transatlantic flights combined, and thus should be seen as a serious climate threat (The Guardian, 17.01.2018). The reason for this is 
that many users engage in the process of "mining" for cryptocurrencies, primarily Bitcoin, whose value exploded in the year 2017. "Mining" for cryptocurrencies means that users employ computer processing power to try to decrypt the algorithms used to code the currencies, a result achieved by "brute force" - trying out trillions of combinations of bits until a match is found. Decrypting a currency unit or unit set typically brings significant payoff to a random user. However, no real value is created in the process; instead, the activity consumes vasts amounts of energy and worsens the climate crisis. The Guardian (17.01.2018) warns that: "Burning more electricity increases your chances of winning, but correspondingly decreases everyone else's - and so they have a motivation to burn more electricity in turn". What is more, if the price of a cryptocurrency increases, the incentives to "mine" for it increase (idem). In game-theoretical terms, Bitcoin or cryptocurrency "mining" leads to spiraling incentives to consume more processing power, because the expected individual payoffs are enhanced, regardless of the environmental effects.

Many sources signal that cryptocurrencies generate bubbles that invariably burst at a certain point, leaving behind lost investments. The Guardian (18.01.2018) points out to the violent fluctuations experienced by Bitcoin within the last weeks: the cryptocurrency lost $40 \%$ of its value within a few weeks, but still remained at levels ten times higher than one year before. The extreme surge in value was not based on people's belief that Bitcoin would one day become a leading world currency, but simply on their expectations that Bitcoin's price would continue to rise (idem). Cryptocurrencies were also associated with the financing of illegal activities or money laundering, thus a great need for their regulation emerges (Dibrova, 2016). Announcements made by governments that they might outlaw cryptocurrencies, along with the other reasons for criticism, hit the currencies very hard, leading to a free fall of the market at the beginning of 2018, as can be seen in the section on empirical results. Nevertheless, to end this section on an optimistic note, the blockchain technology is expected to have a lasting impact, transforming the financial system "by removing the need for banks to act as intermediaries" (The Guardian, 18.01.2018). Leon et al. (2017, p. 298) also suggest that, "if investigated adequately and implemented correctly, safely and securely", the technologies described in this chapter "have the potential for a paradigm shift on data storage and processing" and on "data availability and integrity".

\section{Methodology}

Elendner et al. (2017) perform an advanced analysis of cryptocurrencies as alternative investments for portfolio diversification strategies. Among others, they study the cryptocurrencies' distributions of market capitalization, their risk and return structure, liquidity measures as well as correlations between returns. They also provide valuable information about the development of individual currencies (with a focus on the most important ones), and their history, trends, trading platforms and conditions. A unique and highly innovative contribution to the field was brought by Härdle and Trimborn (2015), who developed a cryptocurrency index (CRIX), available at crix.hu-berlin.de, which evaluates the market performance of the leading currencies, similarly to stock market valuations.

The present study follows closely some of the research methods employed by Elendner et al. (2017), but expands the time frame from two and a half years to about five years, in order to widen our perspective on cryptocurrency development. Based on data from Coinmarketcap.com between April 2013 and February 2018, I look at the distributions 
of the listed cryptocurrencies' market capitalizations and the interplay between the sheer number of currencies and their market volume. I briefly discuss their growth rates, cumulative shares and volatility. My main research hypothesis, on the lines of Elendner et al. (2017), is that cryptocurrencies are subject to high growth and large volatilities.

\section{Results and discussions}

A quick glance at Figure 1, which shows a global chart of the total market capitalization for all cryptocurrencies between April 2013 and February 2018, reveals one of the main hurdles with the analysis of the currencies. Their development from the last 12 months was so explosive that the growth details until 2016 become obscured. This generated the need to segment the entire period into several portions. I analyze the period April 2013 to October 2016 in the next subsection using by-yearly data. Further, due to the accelerated expansion, I use by-monthly data for the period April 2017 to February 2018 and I break it down into two segments: April 2017 to December 2017 and December 2017 to February 2017, where the market reached a peak and then crashed. For each of the resulting three periods I generate dynamic histograms, where the time intervals become ever shorter, due to intense changes in the last period; I place special emphasis on this last period.

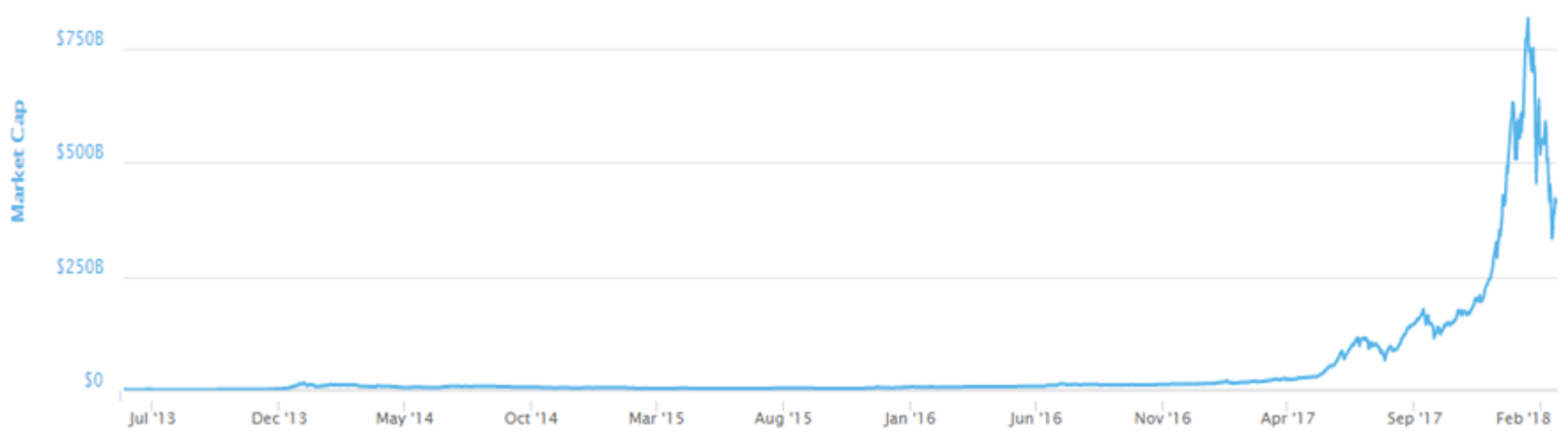

Figure 1. Market capitalization for cryptocurrencies ( $\$$ billions), between Apr 28, 2013 and Feb 10, 2018

Source: https://coinmarketcap.com, edited by the author

The period April 2013 to October 2016: growth and consolidation

At the beginning of the period of analysis, in April 2013, there were only 7 cryptocurrencies with a market capitalization of only $\$ 1.6$ billion, out of which Bitcoin, with its remarkable first-mover advantage, had a share of almost $95 \%$ of the market. Figure 2 shows by-yearly data on number of currencies and market capitalization in $\$$ billions. As corroborated by Elendner et al. (2017), I found that the year 2014 was a highly prolific period for cryptocurrencies, with Altcoins being created every day (idem) and growing more than tenfold in number, from 32 in October 2013 to 460 in October 2014. In the subsequent periods the number of currencies stagnated, barely reaching 522 in October 2016. Market capitalization fell between April 2014 and April 2015 from $\$ 6.3$ billion to $\$ 3.5$ billion, thus lost almost half of its value. Since the fall in value coincided with the rise in number, it might be interesting to see who were the winners and losers of that period. This matter is left to future research. Overall, market capitalization reached $\$ 13.4$ billion at the end of the period, in October 2016. I regard this period as one of intense growth and consolidation. 


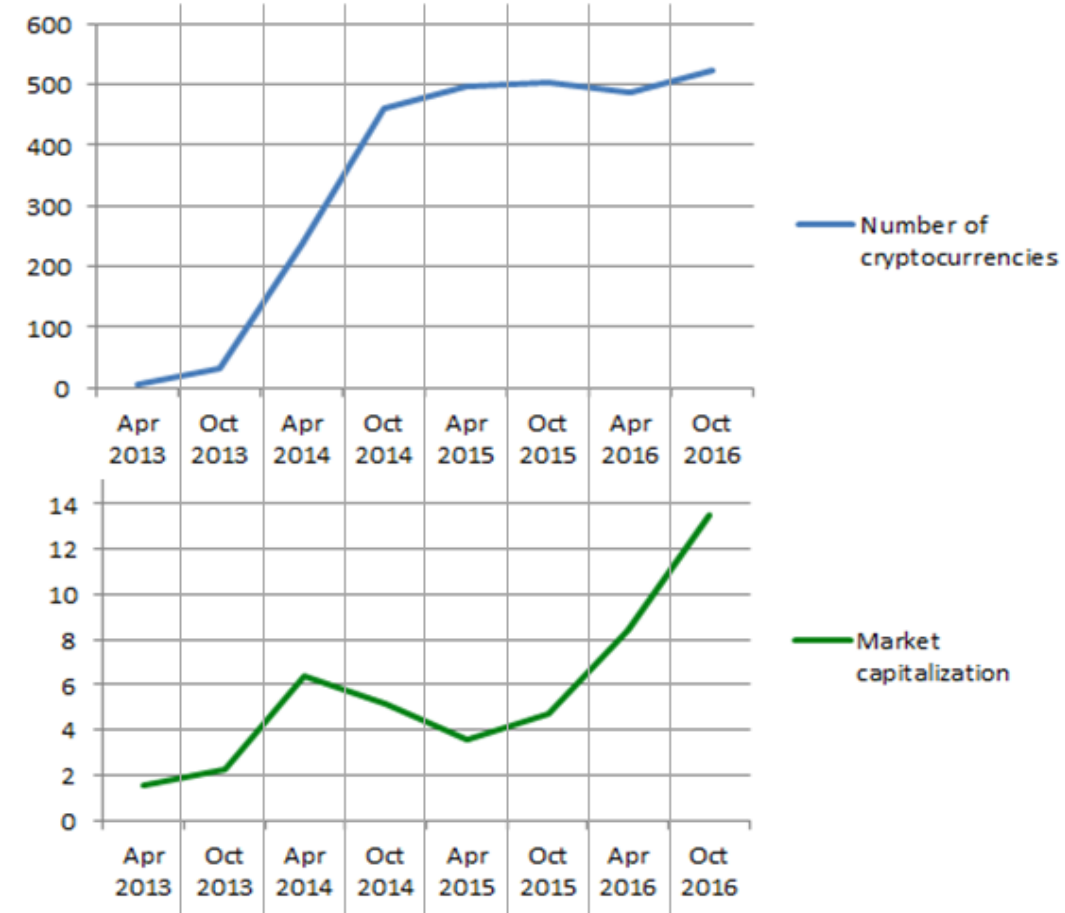

PICBE | 924

Figure 2. Number of cryptocurrencies and market capitalization (\$ billions), 2013-2016

Source: Author's own computations, based on data from https://coinmarketcap.com

Figure 3 shows dynamic histograms of Log10 of market capitalizations in three time points from April 2014 to April 2016. These dynamic histograms have the advantage that they include the entire class of listed cryptocurrencies and add the dimension of time, thus they can be seen as three-dimensional histograms. The charts are adapted to the same scale. I ran analysis of these distributions and found that they, as well as the ones from Figures 5 and 6, are log-normally distributed, with means and medians almost equal, low standard deviations as well as small values for skewness and kurtosis. The means of the three distributions in Figure 3 are 4.88, 4.21 and 4.74 for April 2014, 2015 and 2016 respectively, showing distributions centered on cryptocurrencies with market value between $\$ 10.000$ - $\$ 100.000$. The means reflect the fall of the market capitalization in April 2015, as seen in Figure 2. Simultaneously, the number of currencies increased sharply in 2015, which made the second distribution pointier, but with lower center. Finally, the third distribution is significantly higher and fatter than the first one, while their centers are almost equal. This shows consolidation of the market: the number of currencies was higher, they were more valuable and superstar currencies (with Log10 between 8-10, showing capitalizations of $\$ 100$ million - $\$ 10$ billion) were more numerous. 


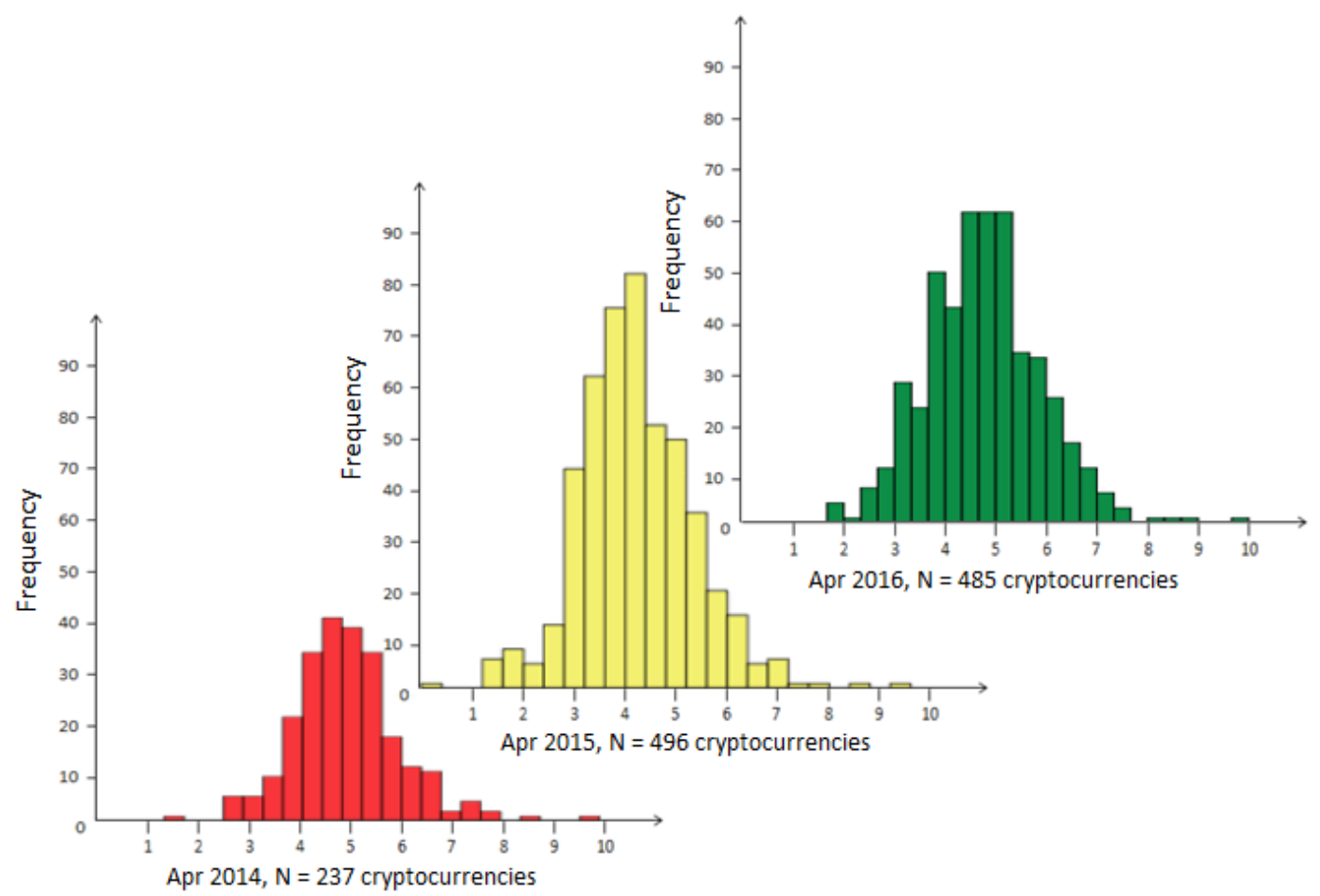

PICBE | 925

Figure 3. Histograms of Log10 market capitalizations over time, Apr 2014 - Apr 2016

Source: Author's own computations, based on data from https://coinmarketcap.com

\section{The period April 2017 to February 2018: exponential growth and crash}

To understand the discrepancy between the period analyzed in the previous section and this one, it is helpful to look at the growth rates of market capitalization. Between April 2013 and April 2017, cryptocurrencies were growing at an average rate of about $435 \%$ per year. Between April 2017 and January 2018, they grew at $345 \%$ per month! From October 2016, the last data point from Figure 2, market capitalization more than doubled until April 2017, where the analysis of this section starts.

As seen in Figure 4, the number of cryptocurrencies followed a fairly linear course, from 581 currencies in April 2017 to 1134 in February 2018. However, market capitalization grew explosively from $\$ 28$ billion in April to $\$ 334$ billion in December, before it more than doubled to $\$ 824$ billion in January and finally crashed to $\$ 443$ billion in February, a true bubble that eventually burst. 


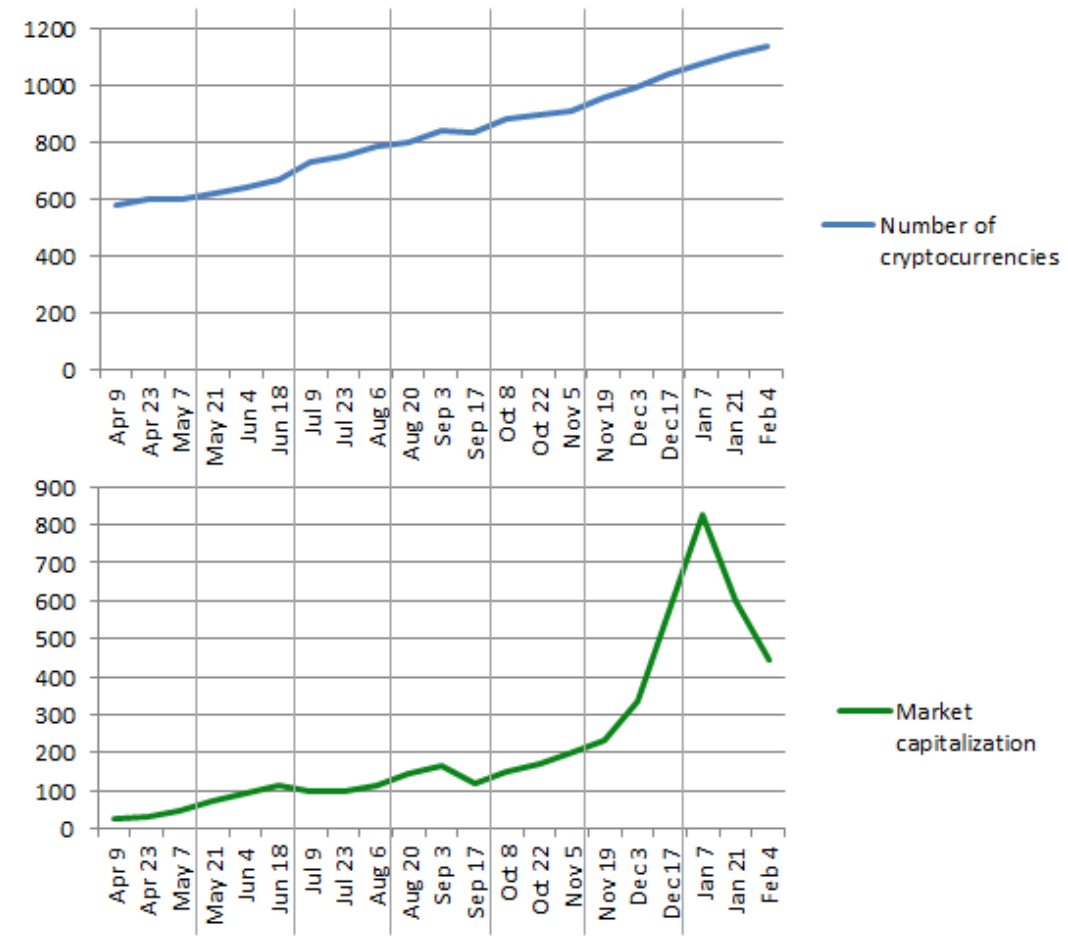

PICBE $\mid 926$

Figure 4. Number of cryptocurrencies and market capitalization ( $\$$ billions), Apr 2017 to Feb 2018

Source: Author's own computations, based on data from https://coinmarketcap.com

Figures 5 and 6 show the last dynamic histograms of market capitalizations. Since the pace of growth was so much accelerated between April 2017 and February 2018, I took intervals of four months between April and December and then zoomed in even more and took monthly data between December and February, to obtain comparable results and grasp the market's final movements. I re-instate the idea from the previous section that all these charts are log-normally distributed. In Figure 5, the means for April, August and December are 5.14, 5.91 and 6.22, showing that the average cryptocurrency surpassed $\$ 1$ million in value by December. The distribution in August is both pointier and fatter than in April, while in December it becomes very pointy, showing that many new currencies were created, and they also achieved high capitalizations very fast. Superstar currencies, evidenced by the right tails of the distributions, also increased in number and in December Bitcoin surpassed the $\$ 100$ billion mark. In Figure 6, the distributional mean continued to rise to 6.85 in January, and three currencies were megastars of over $\$ 100$ billion in capitalization: Bitcoin, Ripple and Ethereum. Finally, when the market crashed in February by losing almost half of its value compared to January, the mean only fell to 6.67, the total number of currencies continued to rise, and the loss fell on the shoulders of the three megastar currencies; all except Bitcoin fell back to under $\$ 100$ billion. 


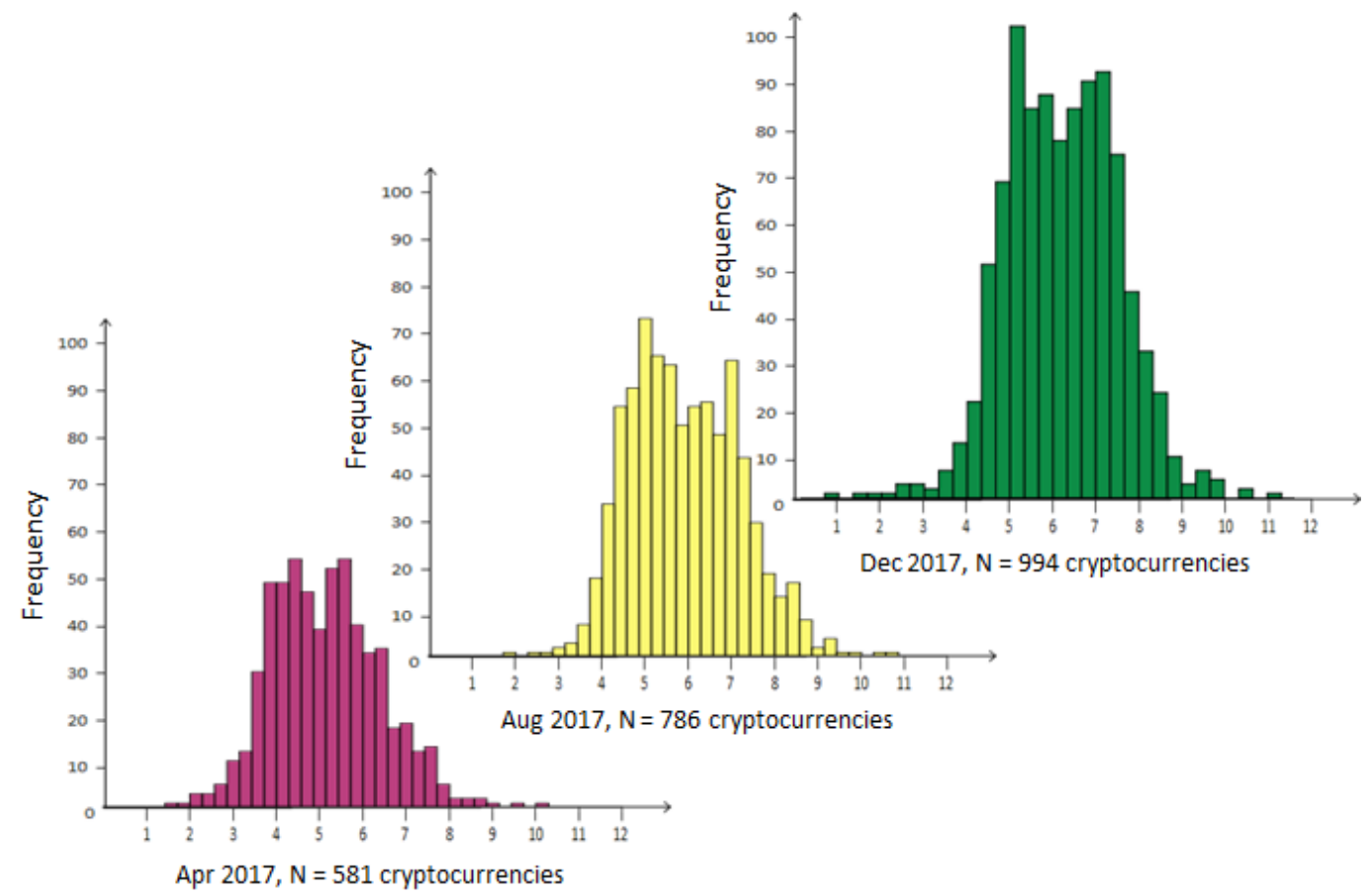

PICBE | 927

Figure 5. Histograms of Log10 market capitalizations over time, Apr 2017 - Dec 2017

Source: Author's own computations, based on data from https://coinmarketcap.com

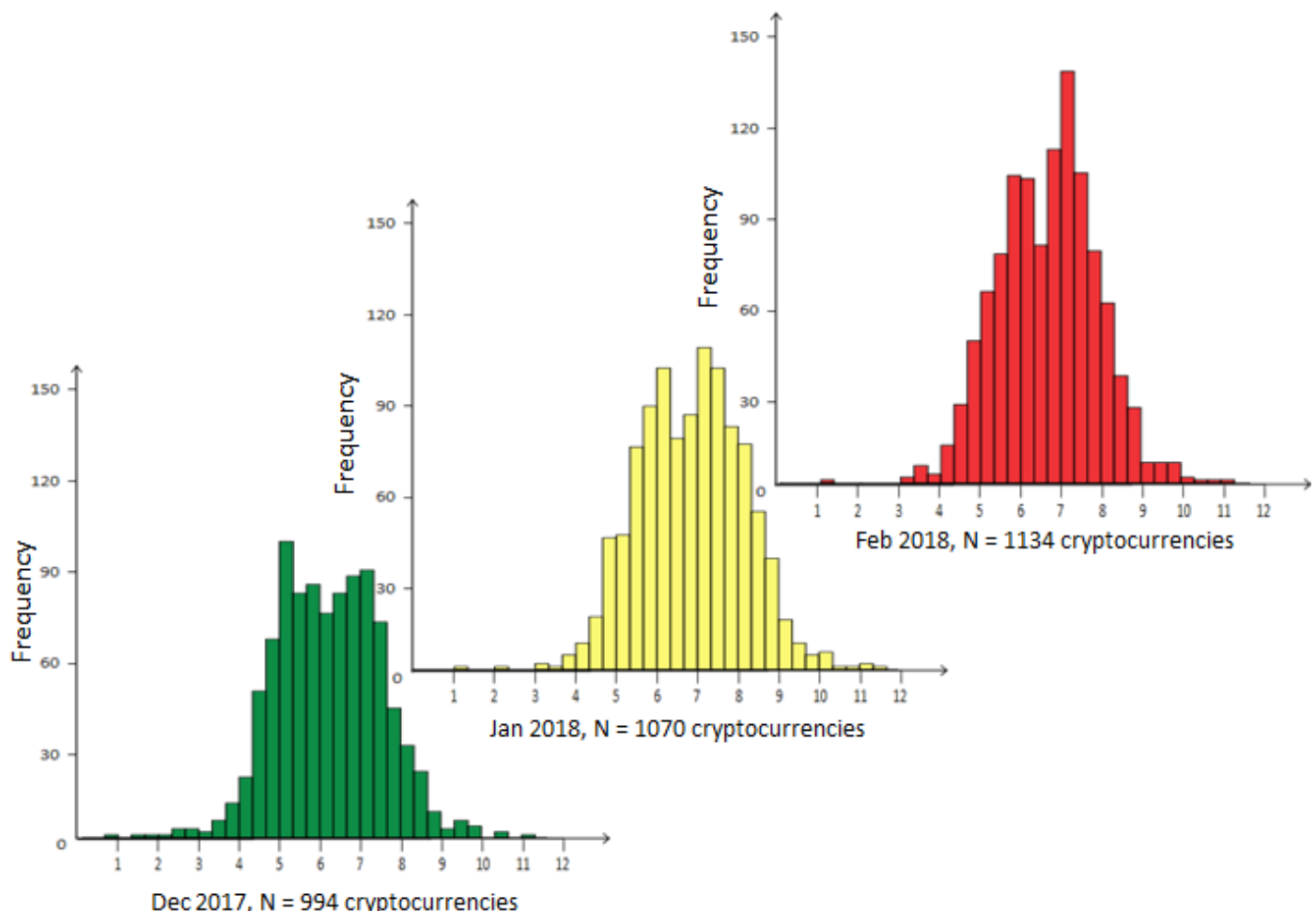

Figure 6. Histograms of Log10 market capitalizations over time, Dec 2017 - Feb 2018

Source: Author's own computations, based on data from https://coinmarketcap.com

\section{Analysis of cumulative shares}


Figure 7 shows that the cumulative shares of Bitcoin, the world leading cryptocurrency, and of the other top six biggest currencies have continually decreased each year from April 2013 until April 2017. However, one must take into account that the denominator is much larger, as the market capitalization was about $\$ 1.6$ billion in the first period, compared to $\$$ 27.8 billion in the last period. Thus, the leading seven currencies gave away market share to the other hundreds of currencies.

PICBE $\mid 928$

Figure 8 focuses on the very last period, the last rise and crash between December 2017 and February 2018. The bubble generated by Bitcoin burst very fast: Bitcoin rose from \$ 186 billion in December to \$288 billion in January and fell to $\$ 153$ billion in February, showing signs that the speculative phenomenon reached its limits. Ethereum, the main alternative to Bitcoin, rose vigorously from $\$ 45$ to $\$ 106$ billion from December to January, but fell only slightly to $\$ 92$ billion in February, as investors shifted their attention to the younger currency brother. All the other currencies, highlighted in orange, had market capitalizations of 67, 258 and 140 billion dollars in the three months of analysis, which shows that Bitcoin took the hardest hit. Overall, the number of cryptocurrencies continued to rise from 994 in December to 1134 in February, as developers continued to believe that they can squeeze money out of the phenomenon.

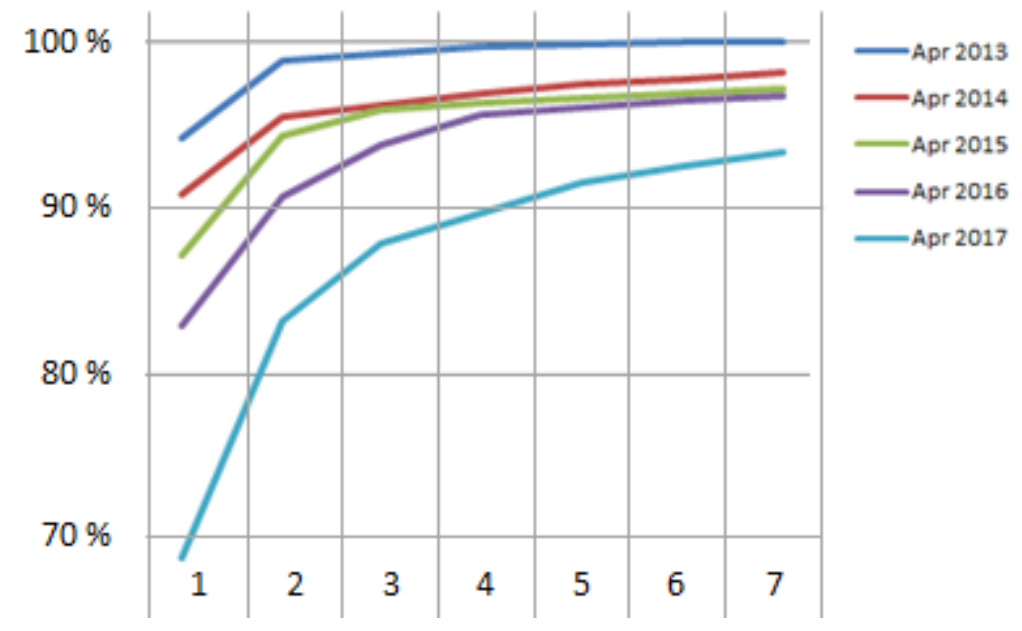

Figure 7. Cumulative shares (in percent) of the top seven cryptocurrencies by market capitalization, yearly, Apr 2013 - Apr 2017

Source: Author's own computations, based on data from https://coinmarketcap.com 


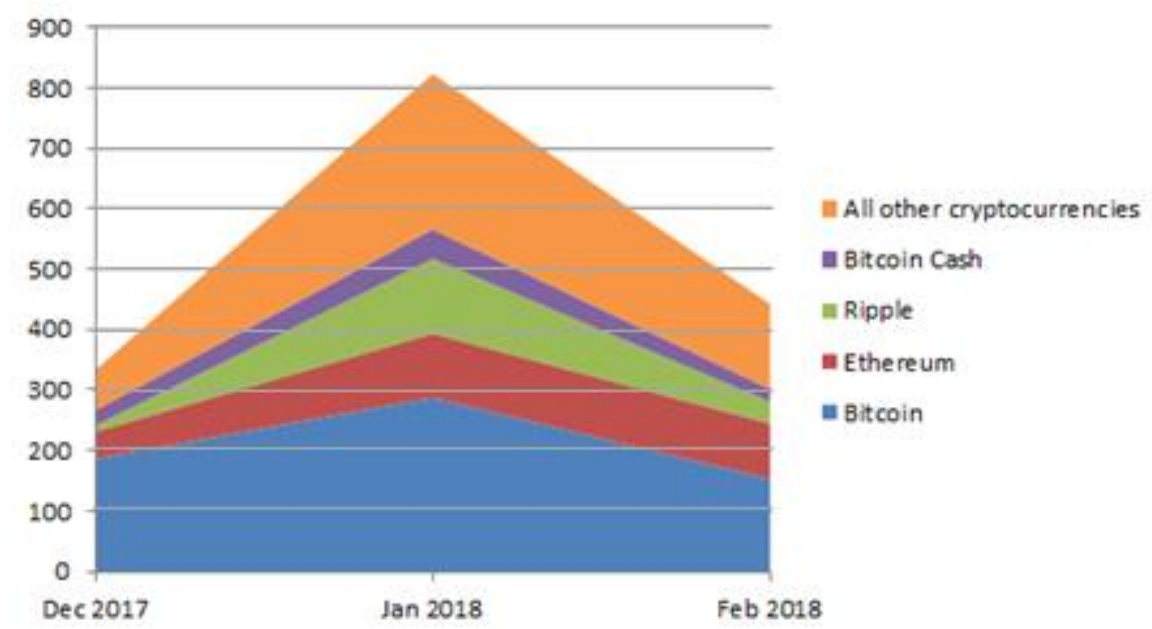

PICBE $\mid 929$

Figure 8. Market capitalizations for the top four cryptocurrencies versus all others, Dec 2017 - Feb 2018

Source: Author's own computations, based on data from https://coinmarketcap.com

\section{Conclusion}

This paper has looked at the development of cryptocurrencies over a large time horizon, from the currencies' infancy in 2013 until their recent surge and crash at the beginning of 2018. Cryptocurrencies' initial period of intense growth and consolidation was partially fueled by their resilience and efficiency as means of exchange, partially by Ponzi schemes and human greed. In recent months, I found a phenomenon of exponential growth and violent volatility. I attribute it to intense speculation, not based on a true belief that Bitcoin would become the new world currency, but only on the expectation that it would continue to grow indefinitely. After the "mining" and climate scandals, followed by governments' threats to ban the currencies, the bubble inevitably started to burst and the explosive market crashed. Bitcoin, which had been artificially inflated, had the most to suffer from the crash. The other currencies fell too, albeit at a lower rate. To this day, the number of currencies is even larger than before the crash, showing that the phenomenon is here to stay.

A limitation of the present study is that not the entire universe of cryptocurrencies is included, but only a subset, the one where data was available on Coinmarketcap.com. There may be thousands more cryptocurrencies active in the market. A further limitation is that this study performs an aggregate analysis of cryptocurrency market capitalization, but does not go into details about individual currencies.

One avenue for future research would be to study cryptocurrencies by the industries they are employed for. Another relevant direction would be to analyze them geographically, by volume of usage in each country, or by regulatory mechanisms. Future researchers could study the rate at which new cryptocurrencies vanish over time, and compute an indicator of volatility.

The crisis experienced by the current financial regime, compared by Dula and Lee (2017) to "death by a thousand cuts" (p. 2), whose pains are inflicted on us, the general public, could be a story taken from "Tales from the Crypt". The industry absorbs large amounts of our money to generate global debt, uncertainty and lacking economic growth (idem). The initial promise held by cryptocurrencies to return financial power to the people 
seems to evaporate in the midst of greedy and gullible behavior. The current state of virtual currencies, with their high propensity for fly-by-night activities, speculation and violent volatility endangers the currencies' potential to become a viable alternative to traditional money. However, the revolution initiated by Fintech and the blockchain technology is no longer stoppable: it will transform financial activities in the same way the Internet changed everything. Our main concern should be to find effective methods of regulation in order to un-tap the real potential of cryptocurrencies.

\section{References}

Accenture (2015). The Future of Fintech and Banking: Digitally disrupted or reimagined? https://www.accenture.com/_acnmedia/PDF-8/Accenture-Future-Fintech-BankingASG.pdf. Accessed 06.02.2018.

Baron, J., O'Mahony, A., Manheim, D., and Dion-Schwarz, C. (2015). The Current State of Virtual Currencies. In National Security Implications of Virtual Currency: Examining the Potential for Non-state Actor Deployment (pp. 5-22). RAND Corporation.

Dibrova, A. (2016). Virtual currency: new step in monetary development. Procedia - Social and Behavioral Sciences, 229, $42-49$.

Dula, C. and Lee, D.K.C. (2017). Reshaping the Financial Order. In Lee, D.K.C. and Deng, R. (Eds.). Handbook of Blockchain, Digital Finance, and Inclusion, Vol. 1 (pp. 1-18). Academic Press, Elsevier.

Elendner, H., Trimborn, S., Ong, B., Lee, T.M. (2017). The Cross-Section of Crypto-Currencies as Financial Assets. In Lee, D.K.C. and Deng, R. (Eds.). Handbook of Blockchain, Digital Finance, and Inclusion, Vol. 1 (pp. 145-174). Academic Press, Elsevier.

Härdle, W., Trimborn, S. (2015). Crix or Evaluating Blockchain Based Currencies. Oberwolfach Report No. 42/2015 "The Mathematics and Statistics of Quantitative Risk".

Lee, D.K.C. and Teo, G.S. (2015). Emergence of FinTech and the LASIC Principles. Journal of Financial Perspectives. 3 (3), 1-26.

Leon, D.C., Stalick, A.Q., Jillepalli, A.A., Haney, M.A. and Sheldon, F.T. (2017). Blockchain: properties and misconceptions. Asia Pacific Journal of Innovation and Entrepreneurship, 11 (3), 286-300.

Mikolajewicz-Wozniak, A. and Scheibe, A. (2015). Virtual currency schemes - the future of financial services. Foresight, 17 (4), 365-377.

The Guardian (03.02.2015). What you should know about fintech and its positive powers. https://www.theguardian.com

The Guardian (07.07.2015). You need never use a bank again. Here's why. https://www.theguardian.com

The Guardian (07.01.2018). The Guardian view on cryptocurrencies: a greater fool's gold. https://www.theguardian.com

The Guardian (17.01.2018). Bitcoin's energy usage is huge - we can't afford to ignore it. https://www.theguardian.com

The Guardian (18.01.2018). Bitcoin bubble is bursting and has a long way to fall, economists warn. https://www.theguardian.com 